\title{
Natural History and Survival in Operated Thoracic Aortic Aneurysm Patients
}

\author{
Mohamad Bashir ${ }^{1 *}$, Amer Harky ${ }^{1}$, Matthew Fok ${ }^{2}$, Ben Adams ${ }^{1}$, Prity Gupta ${ }^{1}$, Rakesh Uppal ${ }^{1}$ and Aung $\mathbf{0 o}^{2}$ \\ ${ }^{1}$ Department of Cardiac Surgery, Barts Heart Centre, St Bartholomew's Hospital, London, United Kingdom \\ ${ }^{2}$ Liverpool Heart \& Chest Hospital, Thoracic Aortic Aneurysm Service, UK
}

Submission: February 03, 2017; Published: March 27, 2017

*Corresponding author: Mohamad Bashir, Department of Cardiac Surgery, Barts Heart Centre, St. Bartholomew's Hospital, London, UK, Email: drmbashir@mail.com

\section{Introduction}

This paper forms the second of a two part series on the natural history and survival of Thoracic aortic aneurysms (TAA), in which this part focuses on patients following surgical operation [1]. Surgical intervention on the thoracic aorta has historically been thwart with such high rates of morbidity and mortality that in the past surgeons have previously given all hope of being able to successfully operate on patients suffering from TAAs. It has required innovation, persistence and pioneering surgeons to achieve the reduced morbidity and mortality of today's acceptable rates.

The natural history of thoracic aortic aneurysms (TAA) is still highly debated within the world of aortic surgery. Particular considerations are made to the aetiology of aortic disease. Certain genetic conditions, particularly those affecting connective tissue, predispose patients to development of thoracic aortic aneurysms, infamously Marfan syndrome. Pertaining to Marfan, it is well documented that these patients are not only susceptible to the development of thoracic aortic disease but are at a significantly higher risk of reoperation following surgery that is not seen in patients suffering from aneurysms of the degenerative type [2]. There is a vast array of genetic diseases that have be attributed to the development of TAAs other than Marfan syndrome.

However, existing research into the natural history of this patient is limited and this is reflective of the rarity of these diseases including; marfans, familial nonsyndromic thoracic aortic aneurysm syndromes, vascular ehlers-danlos syndrome, Loeys-Dietz syndrome, bicuspid aortic valves as well as others. The extent of aneurysm can be considered to increase the risk of morbidity and mortality following surgery. The thoracoabdominal aneurysm carries the highest risk of mortality and morbidity rates on both operated and non-operated patients [3].

This paper outlines a brief surgical history and key developments in TAA surgery setting the stage of how TAA surgery has developed with time. It describes the genetic diseases associated with thoracic aortic aneurysm and how aetiology is linked to mortality and morbidity. Furthermore, this paper explores how post-operative survival following open surgical repair has improved over time, current morbidity and mortality and how this relates to aetiology. We focus on patients that have undergone elective surgical repair opposed to those in an emergent situation and those undergoing open repair.

\section{Methods}

An extensive literature search was performed, to assess the scope of literature currently available. A search of major medical databases was carried out including PubMed and the Cochrane Central Register of Controlled Trials (CENTRAL). Limits were placed on all articles to those published between 1990 and 2013, and to those written in English only, except when assessing literature in regards to historical developments when these limits were removed. Search terms were charted to subject headings and combined using Boolean operations. Search terms included; natural history, thoracic aortic aneurysms, aneurysm size, risk factors, survival rates, Marfan syndrome, medical therapy, aneurysm growth, aortic arch. Abstracts of papers found in the literature search were read to assess suitability for inclusion in this review. Reference lists of papers found in the literature search were manually searched to assess suitability for inclusion in this review.

\section{Historical Perspective}

The word aneurysm has its roots derived from the ancient Greek words aneurusma and eurunein, meaning to dilate and to widen. Development for treatments of aortic aneurysms throughout history has focused on abdominal aortic aneurysms (AAA). This is in part due toits larger prevalence and easier detection clinically, particularly before the advent of radiological imaging. Many principles underpinning surgical correction of thoracic aortic aneurysms (TAA) have foundations in treatments developed for AAA. The first documented evidence of aortic 
aneurysm repair dates back to Egyptian times on the ancient medical papyrus scrolls found in the "Book of Hearts" where it describes that tumor of the arteries can only be cured by magic [4].

The initial treatments developed for aortic aneurysms were that of simple ligation proximal to the aneurysm. A technique that had been first described for peripheral aneurysms by the Greek surgeon Antyllus, in the first half of the second century AD $[4,5]$. Notably, this technique was used by Astley Cooper, a pupil of the infamous John Hunter, who ligated an AAA, understandably this technique was used with limited success and mortality and detrimental morbidity remained high. Despite the poor survival rates this practice continued. Marin-Theodore Tuffier is credited as the first surgeon to attempt this technique in TAAs. He used catgut to ligate both proximal and distal to an ascending aortic aneurysm [6]. His endeavor in 1901 was unsuccessful, as were attempts on a subsequent three patients.

Renewed attempts to consolidate aneurysms through the promotion of coagulation, by means of the introduction of foreign material was tried in AAA, again with limited success. Moore et al. [7] was the first surgeon to attempt this procedure on a TAA protruding from the right side of the sternum in the second intercostal space in 1864. Moore placed 26 yards of iron wire within the aneurysm. Initially, the patient did well but did not survive past day 4 . Surgeons attempted this technique with other foreign materials including different metals and even one case describing watch springs. However, all were met without success. A small review of these practices in the 1900 s revealed a $100 \%$ mortality in TAAs treated with the method of placing wire into the aneurysm described by Moore $(n=8)$. The same review describes a modified method by Corradi, which involved passing a galvanic current through a wire inserted into the aneurysm, later named the Moore-Corradi method. This method produced more favorable results, and of the 17 patients described in the review undergoing this procedure, there was a $24 \%$ recovery rate [8]. The most successful development in the coagulation method was described in 1938 by Blackmore and King. In a case series of 63 syphilitic aneurysms, their electrothermic coagulation method gave a $27 \%$ survival rate $2-11$ years post operatively, and the majority of surviving patient's symptom free.

The first report of cellophane wrapping as a method to induce periarterial fibrosis in a subclavian aneurysm was described in 1943 by Harrison \& Chandy [9]. This method produced reduction of the aneurysm in a long and gradual process requiring an average of 19 months. This method was tried in TAAs, however limited success was achieved with unpredictable results as reported by Poppe in 1948 [10]. Interestingly, Albert Einstein, who suffered from an AAA was treated with this method, and survived a further 5 years before rupture.

It was not until 1951 that direct treatments for aneurysms evolved, rather than the indirect methods of ligation, wiring and cellophane wrapping. Charles Dubost, of France, resected an AAA, and replaced the diseased segment with an allograft obtained from a young girl 3 weeks previous $[5,10]$. In the same year Lam \& Aram [11] followed Dubost and resected a descending TAA with allograft replacement. Lam's patient survived the operation but developed a mediastinal abscess ultimately leading to his death. Despite this the operation was replicated with success by other notable surgeons including DeBakey \& Cooley [12]. It led to the development of numerous allograft aortic banks worldwide in anticipation of a growing number of surgeries to the aorta. However, these methods were introduced before the introduction of cardiopulmonary bypass (CPB) and although operative and post-operative survival was increasing it gave rise to a significant risk of paraplegia due to aortic ischaemia. It is at this critical time, before the dawn of CPB, important research to prevent operative morbidity evolved including; induced hypothermia and shunts. Furthermore, development of artificial aortic substitutes were researched during this time, and DACRON was deemed to be the most suitable for graft implantation, first used by DeBakey in the 1950s, and still widely used in vascular surgery today.

At this time repair of ascending and aortic arch aneurysms still remained an unachievable goal by resection due to the unpreventable risk of cerebral ischaemia. This changed with the advent of CPB when Cooley and DeBakey were the first to successfully resect an ascending thoracic aortic aneurysm and replace it with anallograft [12]. Repair of an aortic arch aneurysm came in 1957 with successful resection and replacement with a homograft, again by DeBakey et al. [13]. These operations led to the widespread uptake in TAA resection with either artificial DACRON or allograft replacement.

Recently, endovascular repair has excited the vascular world, particularly when Dake et al. [14] successfully repaired a thoracic aortic aneurysm in 1994 with this technique. However, with the first endovascular grafts being FDA approved in 2005 little long term data is available. Currently, it is AAAs that commonly are treated via an endovascular approach. With regards to TAA, endovascular repair remains a source of great debate, in terms of long term survival, long term durability of the grafts, and operative morbidity of paraplegia and stroke. Hybrid endovascular approaches to thoracic aortic aneurysm repair will undoubtedly remain at the forefront of modern research in these cases, however at present open repairs remain the standard treatment with more substantial data, and practice qualifying its use.

\section{Aetiology}

There exists conflict surrounding the aetiology of TAAs in the literature. The prevailing consensus, reflected in the most recent guidelines for thoracic aortic disease, cites medial degeneration as the primary causative factor for the majority of TAAs [15]. Historically, atherosclerosis was credited as the main cause for aortic aneurysms, which was based upon findings from post mortems $[16,17]$. Although atherosclerotic lesions 
are commonly associated with thoracic aneurysms, typically they are preceded by medial degeneration $[16,18,19]$. This key point is still not conclusive proven. Patel et al. [19] wrote a detailed review discussing the pathogenesis of ascending and aortic arch aneurysms. They describe three separate pathological aetiologies namely; degenerative, Marfan and other inherited connective tissue diseases, and syphilitic aneurysms. Degenerative aneurysms undergo a classical and specific pathological process. Post mortem examinations reveal greatly reduced elastin content within the ascending aorta, the media of the aneurysms displays a lack of smooth muscle cells [16]. Cystic medial degeneration can be observed in the media, which is described microscopically as fragmentation of elastin fibers.

Although this process is widely regarded to be associated with aging, the recent analysis of the large Yale TAA database reveals a strong familial component [20]. Matrix metalloprotease (MMPs) are recognized to play a critical role in aneurysm formation [21,22]. MMPs are still being studied in vitro and in vivo, however it is known that MMPs significantly contribute to proteolysis of the aorta causing the aneurysm to expand. It is this observation that has developed a lot of interest lately in medical treatment of TAAs. In the past the majority of cases could be attributed to syphilitic infection, however with the modern era of screening and antibiotics it is now a rarity and is not discussed here.

In the absence of connective tissue disease, current evidence points toward a strong inherited genetic phenotype of accelerated medial degeneration as the primary culprit for TAAs. However, there are many risk factors that contribute to formation of a TAA, which are discussed below. Therefore, the likelihood that this is a multi-factorial disease, of genetics and lifestyle factors, is the consensus of most papers [15].

\section{Genetically Triggered Thoracic Aneurysm Syndromes \\ Marfan syndrome}

Classically, Marfan syndrome has been the most extensively studied connective tissue disorder in relation to thoracic aortic disease. Marfan syndrome is an autosomal dominant genetic disorder of the FBN1 gene encoding for fibrillin-1 [23]. Usually fibrillin-1 is found in microfibrils located in the extracellular matrix. Microfibrils play a crucial role in maintaining the elastic fibers of connective tissues, and it is this that predisposes Marfan patients to TAAs $[24,25]$. It is a rare disease with an incidence of approximately 1 in 5000, displaying a high penetrance and variable phenotype. Diagnosis is made using the 2010 revised Ghent nosology, superseding a diagnostic criteria primarily based on clinical features alone [26]. The revised criteria critically emphasize the presence of aortic root dilation or ectopic lentis (displacement or malposition of the eyes crystalline lens) in new patients without a family history, as a cardinal feature for a definitive diagnosis. A family history of Marfan syndrome, present in approximately $50 \%$ of patients, is more indicative of a diagnosis and thus requiring only one other factor of; an aortic root aneurysm, ectopic lentis, a pathogenic fibrillin-1 (FBN-1) mutation, or systemic features defined in the Ghent Nosology, to formulate a diagnosis.

It is well documented that approximately $50-90 \%$ of these patients will develop aortic root dilation. Because of this predictable progression, Marfan syndrome has previously been used to extrapolate clinical findings, practice and research, to TAAs of different aetiologies [27-29]. Currently, TAA guidelines segregate Marfan patients into a distinct subset of patients, preferentially indicating earlier surgical intervention for TAA. The evidence for this stems from numerous studies demonstrating a high association with an accelerated growth rate of the aortic root $(0.2-0.3 \mathrm{~cm} /$ year $)[27,30,29]$.

The trend of using Marfan patients for research and extrapolating this to all aetiologies of TAAs has long discontinued. In part, this is due to the obvious differences in pathogenesis and varied clinical findings, and it is now realized substantial variation exists.

\section{Familial non-syndromic thoracic aortic aneurysm syndromes}

Familial Non-syndromic Thoracic Aortic Aneurysm Syndromes are defined as patients who have a first degree relative that suffered an aortic aneurysm but are without a known associated genetic syndrome. Elefteriades et al. [22] have an extensive database of approximately 1200 patients who were diagnosed with TAA in Connecticut [20,22,31,32]. Their analysis of this database identified $21 \%$ of this cohort who had a first degree relative with known or likely aortic aneurysm, in the absence of a connective tissue disorder. Within this subset of patients an autosomal dominant pattern with incomplete penetrance pattern was displayed. This observation has been made before, but due to the rarity and absence of large databases in previous years has not be studied extensively [20]. Elefteriades et al. [22] note that this percentage is likely to be higher as these results were based upon family interview and are subject to bias.

Because this observation is only recently been brought to light within the research world genetic identification of associated genes is still in its infancy. Currently, ACTA 2, MYH11 and TGFBR2 are implicated as the primary gene candidates associated with this syndrome. As genetic testing becomes more widely available and readily understood in the general public, ACTA 2 detection is recommended in suspected familial TAAs. In the future more genes may be tested but this requires further research and time.

\section{Bicuspid aortic valve}

A bicuspid aortic valve (BAV) is well recognized as an independent risk factor for aortic aneurysm [33-35]. This congenital cardiac malformation is reported to exist in the general population at a prevalence of $1-2 \%$. In this subset of patients, one study found thoracic aortic dilation at a prevalence 
of $88 \%$ in those over the age of 80 . It is known that BAVs can show an autosomal dominant inheritance in families, which is seen in approximately $9 \%$ of TAA cases [36].

Davies et al. [37] were the first to show that bicuspid aortic valves are associated with a increased aortic aneurysm growth rate. Because the risk of TAA formation is so significant in these patients the latest TAA guidelines recommend intervening surgically earlier, when their aneurysms reach a size of $5.0 \mathrm{~cm}$ [15]. The pathogenesis remains a mystery. However, an aortic aneurysm associated with a BAV is histologically similar to that of Marfan patients chiefly; medial degeneration, increased metalloproteinase activity and decreased FBN-1 in the aortic wall. Combined this leads to increased aortic aneurysm growth rates with a propensity for rupture earlier than TAAs not associated with an inherited genetic condition [34].

Of note, co-arctation of the aorta is highly suggestive of BAV (up to $50 \%$ of patients). Originally, the pathogenesis was linked to the common embryological development of the aortic valve and the ascending aorta [35]. This observation suggests that pathological changes are not isolated to the proximal aorta and may well involve the arch and the descending aorta.

\section{Vascular ehlers-danlos syndrome}

Also, referred to as Ehlers-Danlos (ED) syndrome type IV, is another rare autosomal dominant disorder affecting the COL3A1 gene [24]. Typically, these patients have a distinctive facial appearance with an accompanying body habitus and a propensity to develop ecchymoses. It is described as a more serious form of ED syndrome in that blood vessels, particularly arterial vasculature, are prone to rupture. The syndrome causes a deficiency in the synthesis of type III collagen, the main component of connective tissue, the loss of which increases vessel fragility making surgical repair more difficult. These patients have a severely reduced life span approximated at 48 years.

\section{Loeys-Dietz syndrome}

Loeys-Dietz (LD) syndrome is described as an autosomal dominant aortic aneurysm disorder with involvement of other systems [24,27]. The classical triad of features is arterial tortousity and aneurysms, hypertelorism and bifid uvula or cleft palate, or a uvula with a wide base and prominent ridge. Diagnosis is made on mutational analysis in TGFBR1 or TGFBR2, which are genes recently discovered as the primary defect in LD syndrome [38]. Unlike VD syndrome surgical intervention is not complicated by vessel fragility, thus these patients can be managed aggressively in respects to aneurysm treatment. The majority of these patients have aneurysms of the aortic root $(98 \%)$, rupture of which is reported to occur at smaller diameters than other genetic syndromes, thus the bar is further lowered to a diameter of $4.4-4.6 \mathrm{~cm}$ in TAA as an indication for surgical repair [12].

\section{What is the Operative Mortality Following Thoracic Aortic Aneurysm Repair?}

Operative mortality has drastically improved over the last century when thoracic aortic aneurysm repair was not survivable. Significant advances have been seen in Mortality following thoracic aortic aneurysm repair is dependent on many variables, the main ones being; extent and size of aneurysm, patient co-morbidities present, operation underdone on an elective or emergent basis, and recent evidence from the US showing better outcomes in centers who undergo higher volume of cases.

The current 2010 guidelines for thoracic aortic disease describe death following composite valve graft as unusual and the risk is between 1 and 5\% [15]. This risk is however center dependent.

Many centers have reported learning curves in all aspects of thoracic aortic surgery which improvements over time in terms of mortality, which adds to the argument that volume is an important factor in operative mortality. In 2007, Kalkat et al. [39] from Birmingham, UK, interrogated the UK heart valve registry which contained data on 1962 patients undergoing first time composite valve graft replacement and report 30 day mortality as $10.7 \%$. These results include patients operated on an emergency basis as with those with genetic conditions, which may explain the reported higher incidence of mortality compared to that of the 2010 guidelines. In consideration of patients with genetic conditions, Karck et al. [40] from Germany, describe postoperative mortality in Marfan patients as high as $6.8 \%$ in those undergoing composite valve grafts in a retrospective group of 119 patients. A further paper in 2010 by Bernhradt et al describes 30 day mortality in Marfan patients undergoing composite graft replacement as $0 \%$, however this rose to $10 \%$ at follow up. Patel et al also describe a 10\% mortality following Bentall procedure in Marfan patients at 8 year follow up [41]. Other papers describing other genetic syndromes, such as Loeys-Dietz, and composite graft replacement report series too small to draw any relevant conclusions [42]. BAV and ascending aorta repair is now a commonly recognized procedure. El Khoury et al. [43] report no hospital mortality following repair of a regurgitant bicuspid aortic valve with aortic root replacement. A BAV does not significantly increase the risk of mortality following operation compared to those with a tricuspid valve.

Aortic arch operations carry a pre-requisite of cerebral protection due to the nature of the procedure. This opens patients to higher risk of mortality, relating to reduced cerebral perfusion, time of operation, cardiopulmonary bypass time, aortic cross clamp times and periods of deep hypothermic circulatory arrest. The 2010 thoracic aortic guidelines quote a 2 to $6 \%$ risk of death in patients undergoing these types of operations [15]. Leshnower et al. [44] report their center experience between 2004 and 2009 encompassing 412 patients and report and 
operative mortality of $7.0 \%$, this included patients undergoing emergency operations. The Mayo clinic reports 9 years of results from 2001 to 2010 of 209 patients and report a procedure specific mortality of $5.5 \%$ and $1.0 \%$ in total arch and hemiarch procedures respectively [45]. Furthermore, the same paper describes how even over 9 years they have seen decreases in rates of mortality from the first half of their study period compared to their second half ( $7.9 \%$ vs $4.5 \%$ respectively). Other centers have reported similar decreases in mortality over short spans of time including Mount Sinai [46,47]. Gega et al. [48] from Yale published results in 2007 using deep hypothermic circulatory arrest as the sole means of cerebral protection. In their study of 394 patients over 10 years they report a mortality rate of $3.6 \%$ in elective cases. Such rapid advancements in aortic arch surgery have led to different techniques being used by different centers worldwide. This adds a further variable that should be considered when studying mortality rates. Although mortality rates vary worldwide, in general mortality rates reported are in the single digits, particularly so in elective repair and modern day aortic arch surgery is performed with low risk of mortality.

Thoraco-abdominal aortic aneurysm surgery represents the most challenging operation that can be undertaken on the aorta. The 2010 guidelines describe an approximate mortality of $10 \%$ in patients undergoing type II thoraco-abdominal repair, again this is center dependent and furthermore this is recognized in the guidelines [15]. Wong et al, describe 305 patients undergoing TAAA repair of which operative survival following elective repair is $6.2 \%$ [49]. In 2007, Coseli et al. [50] report their entire open thoraco-abdominal aneurysm repair encompassing a total of 2286 patients and report 30 day survival rate of $95.0 \%$. Coseli et al have also reported their experience of TAAA surgery in patients with Marfans syndrome, which totally 50 patients between 1986 and 1996. 30 day survival in these patients was $96 \%$. Cambria et al. [51] from Havard, performed 337 operations on the thoracoabdominal aorta, and reported operative mortality of $8.3 \%$. This mortality rate included patients undergoing operations in a non-elective setting and all types of TAAA repair. Endovasular interventions are becoming ever popular in TAAA repair, particularly as hybrid techniques are being developed. However, these are still very much in their infancy. Although there is some published literature on long term data it still represents an area that is currently under close investigation.

\section{Long Term}

The rapid and evolving nature of thoracic aortic surgery means long term survival is hard to assess. Many centers have reported "learning curves" that show even over a ten year period their mortality rates can be reduced by half. Such advancements are not limited to the surgery itself but also to anaesthetic, pre and post-operative management of these patients.

Higgins et al. [52] analyzed a database containing data on all adult patients who had undergone thoracic aortic aneurysm repair in British Columbia which totaled 1960 patients. Longterm survival was $77.7 \%, 59.6 \%$, and $44.7 \%$ at 5, 10 and 15 years, respectively. Survival in the first half of the study was significantly less compared to the second half of the study 74.3\% (95\% CI, 70.6-77.7) versus 60.4\% (95\% CI, 56.6-63.9) respectively. Crawford et al report a similar experience of 605 patients in 1986 and report a 5 year survival of 60\% [53]

Mount Sinai published long term data in 2010 after aortic arch replacement in 206 patients between 1999 and 2009. Bischoff et al. [54] describe at 6 years, $75 \%$ of patients were still alive, compared with $92 \%$ in a matched New York State control population ( $\mathrm{P}<.001)$. In Japan, Minakawa et al analyzed data from 122 patients who underwent total aortic arch replacement. Overall long-term survival was $80.4 \%$ at 5 years and $58.9 \%$ at 10 years. Estrera et al. [55] have published results in 2002 relating to long term survival in aortic arch patients, with long term survival rates $72 \%$ at 5 years and $71 \%$ at 10 years after surgery.

Cambria et al. [51] from Havard Medical School reported their 15-year experience of 337 TAAA repairs survival rates at 2 and 5 years were $81.2+/-3 \%$ and $67.2+/-5 \%$, which in their study is comparable to routine aortic abdominal repair.

Fehrenbacher et al. [3] reviewed 343 patients in their center undergoing TAAA repair or descending aortic aneurysm repair and report the 1, 5, and 10 -year survival rates were $90 \%$, $69 \%$, and 54\%, respectively [2]. Kouchokos et al. [56] looked at survival following TAAA using hypothermic circulatory arrest in 243 patients between 1986 and 2012. They reported a 5 year survival rate of $55 \%$.

Long term survival is hard to assess particularly considering many centers report significant reductions in mortality in as short a time as ten years. This can be attributed to major advances made in this subspecialty, as well as improved anaesthetic, pre and post-operative management. The wealth of techniques and devices available for use also add to variables that can potentially affect long term survival. However, the amount of data available to assess best practice is still in its infancy. It is because of this, thoracic aortic surgery is a rapidly advancing subspecialty which is exciting to see what developments are made in the near future.

\section{Reoperation}

All operations carried out on the thoracic aorta carry a risk of reoperation. It is thought that this risk is reduced with the use of beta blockers. Theoretically, with reduction of the heart rate the blood pressure is subsequently reduced and in turn relieves the pressure that the repair is subjected to from the heart. Beta blockers are also thought to reduce the expansion rate of thoracic aortic aneurysms before operation; however, the use of beta blockers before and after operation is highly debated [1]. To date though, the 2010 guidelines still recommend the use of beta blockers lifelong following diagnosis of aneurysm [15]. 
It is well described that reoperation is significantly increased in patients with Marfan syndrome. Geisbuesch et al. [57] describe that almost half of the Marfan patients who undergo surgical repair will require reoperation. This is well described in centers that deal with high volumes of patients and come across a higher number of Marfan patients [58]. In comparison, Osslen et al. [59] report analysis of the Swedish national healthcare register of patients with thoracic aortic disease, incorporating over 14000 patients. In this paper, Osslen describes a reoperation rate of $7.8 \%$.

However, survival following reoperation in all aetiologies can be described as low. The 2010 guidelines describe the risk of death following reoperation as between 2 and $6 \%$. This is also described in a similar report on Marfan patients by Geisbuesch who describe re-operative hospital mortality between 0 to $1.6 \%$ [14]. Although more common in Marfan patients reoperation is considered a procedure that when undertaken electively can be done with a low mortality rate.

\section{Conclusion}

Modern day thoracic aortic aneurysm surgery is a relatively new specialty, but has roots deeply embedded in history. Mortality rates have remained high until the advent of specialty has progressed at a rapid rate. In general, mortality is higher in patients with a larger extent of aneurysm and those associated with a genetic syndrome. However, TAA surgery can be carried out on an elective basis with excellent results, in terms of postoperative mortality and reoperation. It is of vital importance to understand how operation affects TAAs so we can confer this knowledge to the patient and to be able to improve on our current results. Genetic syndromes represent a rare subset of patients who suffer from aortic aneurysms and they represent an area of medicine for which there remains many unanswered questions. Undoubtedly, considering the pace of discoveries and developments within this specialty in such a short amount of time, we will see research become more focused towards a personalized approach.

\section{References}

1. Bashir M, Fok M, Hammoud I, Rimmer L, Shaw M, et al. (2013) A Perspective on Natural History and Survival in Nonoperated Thoracic Aortic Aneurysm Patients. Aorta 1(3): 182-190.

2. Erentug V, Polat A, Bozbuga NU, Polat E, Erdogan HB, et al. (2006) Cardiovascular reoperations in Marfan syndrome. J Card Surg 21(5): 455-457.

3. Fehrenbacher JW, Siderys H, Terry C, Kuhn J, Corvera JS (2010) Early and late results of descending thoracic and thoracoabdominal aortic aneurysm open repair with deep hypothermia and circulatory arrest. J Thorac Cardiovasc Surg 140(6 Suppl): S154-S160.

4. DeBakey ME (1991) A surgical perspective. Ann Surg 213(6): 499-531.

5. Cooley DA (1999) Aortic Aneurysm Operations: Past, Present, and Future. Ann Thorac Surg 67(6): 1959-1962.

6. Tuffier T (1902) Intervention chirurgicaledirecte pour un anevrisme de la crosse de I'aorte: ligature du sac. Press Med 10: 267.
7. Moore C, Murchison C (1864) On a new method of procuring the consolidation of Fibrin in certain incurable Aneurisms With the Report of a case in which an Aneurism of the ascending Aorta was treated by the insertion of Wire. Med Chir Trans 47: 129-149.

8. Borrie J, Griffin SG (1950) Twenty-seven cases of syphilitic aneurysms of the thoracic aorta and it branches. Thorax 5(4): 293-324.

9. Harrison PW, Chandy J (1941) A Subclavain Aneurysm Cured by Cellophane Fibrosis. Ann Surg 118(3): 478-481.

10. Coselli JS, Green SY (2013) A brief history of aortic surgery: insight into distal aortic repair. J Thorac Cardiovasc Surg 145(3 Suppl): S123-S125.

11. Lam C, Aram H (1951) Resection of the Descending Thoracic Aorta for Aneurysm, a report of the use of a homograft in a case and an experimental study. Ann Surg 134(4): 743-752.

12. Cooley D, DeBakey M (1956) Resection of Entire Ascending Aorta in Fusiform Aneurysm using Cardiac Bypass. J Am Med Assoc 162(12): 1158-1159.

13. De Bakey M, Crawford E, Cooley D, Morris GJ (1957) Successful resection of fusiform aneurysm of aortic arch with replacement by homograft. Surg Gynecol Obstet 105(6): 657-664.

14. Dake M, Miller D, Semba C, Mitchel R, Walker P, et al. (1994) Transluminal placement of endovascular stent-grafts for the treatment of descending thoracic aortic aneurysms. N Engl J Med 331(126): 1729-1734.

15. Hiratzka LF, Bakris GL, Beckman JA, Bersin RM, Carr VF, et al. (2010) $2010 \quad$ ACCF/AHA/AATS/ACR/ASA/SCA/SCAI/SIR/STS/ SVM guidelines for the diagnosis and management of patients with thoracic aortic disease: a Report of the American College of Cardiology Foundation/American Heart Association Task Force on Practice Guidelines, American Association for Thoracic Surgery, American College of Radiology, American Stroke Association, Society of Cardiovascular Anesthesiologists, Society for Cardiovascular Angiography and Interventions, Society of Interventional Radiology, Society of Thoracic Surgeons, and Society for Vascular Medicine. Circulation 121(13): 55: e266-e369.

16. Young R, Ostertag H (1987) Incidence etiology and risk of rupture of aortic aneursyms. An autopsy study. Dtsh Med Wschr 112(33): 12531256.

17. Kunz R (1980) Aneurysms in 35,380 autopsies. Schweiz Med Wochenschr 110(5): 142-148.

18. Bonser RS, Pagano D, Lewis ME, Rooney SJ, Guest P, et al. (2000) Clinical and patho-anatomical factors affecting expansion of thoracic aortic aneurysms. Heart 84(3): 277-283.

19. Patel HJ, Deeb GM (2008) Ascending and arch aorta: pathology, natural history, and treatment. Circulation 118(2): 188-195.

20. Coady MA, Davies RR, Roberts M, Goldstein LJ, Rogalski MJ, et al. (1999) Familial patterns of thoracic aortic aneurysms. Arch Surg 134(4): 361367.

21. Agarwal P, Chughtai A, Matzinger FR, Kazerooni EA (2009) Multidetector CT of Thoracic Aortic Aneurysms. Radiographics 29(2): 537-552.

22. Elefteriades JA, Farkas EA (2010) Thoracic Aortic Aneurysm Clinically Pertinent Controversies and Uncertainties. J Am Coll Cadiol 55(9): 841-857.

23. De Backer J (2009) Cardiovascular characteristics in Marfan syndrome and their relation to the genotype. Verh K Acad Geneeskd Belg 71(6): 335-371.

24. Cury M, Zeidan F, Lobato A (2013) Aortic disease in the young: genetic aneurysm syndromes, connective tissue disorders, and familial aortic aneurysms and dissections. Int J Vasc Med 2013: 267215. 
25. Halme T, Savunen T, Aho H, Vihersaari T, Penttinen R (1985) Elastin and collagen in the aortic wall: changes in the Marfan syndrome and annuloaortic ectasia. Exp Mol Pathol 43(1): 1-12.

26. Loeys B, Dietz H, Braverman A, Callewaert B, De Backer J, et al. (2010) The revised Ghent nosology for the Marfan syndrome. J Med Genet 47(7): 476-485

27. Van Karnebeek CD, Naeff MS, Mulder BJ, Hennekam RC, Offringa M (2001) Natural history of cardiovascular manifestations in Marfan syndrome. Arch Dis Childh 84(2): 129-137.

28. Glower DD (2011) Indications for ascending aortic replacement size alone is not enough. J Am Coll Cardiol 58(6): 585-586.

29. Brooke BS, Habashi J, Judge D, Patel N, Loeys B, et al. (2008) Angiotensin II Blockade and Aortic-Root Dilation in Marfan's Syndrome. N Engl J Med 358(26): 2787-2795.

30. Cook JR, Nistala H, Ramirez F (2010) Drug-Based Therapies for Vascular Disease in Marfan Syndrome: From Mouse Models to Human Patients. Mt Sinai J Med 77(4): 366-373.

31. Elefteriades JA (2008) Thoracic Aortic Aneurysm: Reading the Enemy's Playbook. Curr Probl Cardiol 33(5): 203-277.

32. Elefteriades JA (2002) Natural History of Thoracic Aortic Aneurysms: Indications for Surgery, and Surgical Versus Nonsurgical Risks. Ann Thorac Surg 74(5): S1877-S1880.

33. Della Corte A, Bancone C, Quarto C, Dialetto G, Covino FE, et al. (2007) Predictors of ascending aortic dilatation with bicuspid aortic valve: a wide spectrum of disease expression. Eur J Cardiothorac Surg 31(3): 397-404.

34. Tadros TM, Klein MD, Shapira OM (2009) Ascending aortic dilatation associated with bicuspid aortic valve: pathophysiology, molecular biology, and clinical implications. Circulation 119(6): 880-890.

35. Fedak PW, Verma S, David TE, Leask RL, Weisel RD, et al. (2002) Clinical and Pathophysiological Implications of a Bicuspid Aortic Valve. Circulation 106(8): 900-904.

36. Loscalzo M, Goh D, Loeys B (2007) Familial thoracic aortic dilation and bicommissural aortic valve: a prospective analysis of natural history and inheritance. Am J Med Genet A 143A(17): 1960-1967.

37. Davies R, Kaple R, Mandapati D, Gallo A, Botta D, et al. (2007) Natural history of ascending aortic aneurysms in the setting of an unreplaced bicuspid aortic valve. Ann Thorac Surg 83(4): 1338-1344.

38. Pezzini A, Del Zotto E, Giossi A, Volonghi I, Costa P, et al. (2012) Transforming growth factor $\beta$ signaling perturbation in the LoeysDietz syndrome. Curr Med Chem 19(3): 454-460.

39. Kalkat MS, Edwards MB, Taylor KM, Bonser RS (2007) Composite aortic valve graft replacement: mortality outcomes in a national registry Circulation 116(11 Suppl ): I301-1306

40. Karck M, Kallenbach K, Hagl C, Rhein C, Leyh R, et al. (2004) Aortic root surgery in Marfan syndrome: Comparison of aortic valve-sparing reimplantation versus composite grafting. J Thorac Cardiovasc Surg 127(2): 391-398.

41. Patel ND, Weiss ES, Alejo DE, Nwakanma LU, Williams JA, et al. (2008) Aortic root operations for Marfan syndrome: a comparison of the Bentall and valve-sparing procedures. Ann Thorac Surg 85(6): 20032010 .

42. Williams JA, Loeys BL, Nwakanma LU, Dietz HC, Spevak PJ, et al. (2007) Early surgical experience with Loeys-Dietz: a new syndrome of aggressive thoracic aortic aneurysm disease. Ann Thorac Surg 83(2): S757-S763.
43. El Khoury G, Vanoverschelde JL, Glineur D, Pierard F, Verhelst RR, et al. (2006) Repair of bicuspid aortic valves in patients with aortic regurgitation. Circulation 114: I610-1616.

44. Leshnower BG, Myung RJ, Kilgo PD, Vassiliades TA, Vega JD, et al. (2010) Moderate hypothermia and unilateral selective antegrade cerebral perfusion: a contemporary cerebral protection strategy for aortic arch surgery. Ann Thorac Surg 90(2): 547-554.

45. Thomas M, Li Z, Cook DJ, Greason KL, Sundt TM (2012) Contemporary results of open aortic arch surgery. J Thorac Cardiovasc Surg 144(4): 838-844.

46. Minatoya K, Ogino H, Matsuda H, Sasaki H, Tanaka H, et al. (2010) Is conventional aortic arch surgery justifiable in octogenarians? J Thorac Cardiovasc Surg 139(3): 641-645.

47. Strauch JT, Spielvogel D, Lauten A, Galla JD, Lansman SL, et al. (2004) Technical advances in total aortic arch replacement. Ann Thorac Surg $77(2):$ 581-589.

48. Gega A, Rizzo JA, Johnson MH, Tranquilli M, Farkas EA, et al. (2007) Straight deep hypothermic arrest: experience in 394 patients supports its effectiveness as a sole means of brain preservation. Ann Thorac Surg 84(3): 759-766.

49. Wong DR, Parenti JL, Green SY, Chowdhary V, Liao JM, et al. (2011) Open repair of thoracoabdominal aortic aneurysm in the modern surgical era: contemporary outcomes in 509 patients. J Am Coll Surg 212(4): 569-579.

50. Coselli JS, Bozinovski J, LeMaire SA (2007) Open surgical repair of 2286 thoracoabdominal aortic aneurysms. Ann Thorac Surg 83(2): S862-S864.

51. Cambria RP, Clouse WD, Davison JK, Dunn PF, Corey M, et al. (2002) Thoracoabdominal aneurysm repair: results with 337 operations performed over a 15-year interval. Ann Surg 236(4): 471-479.

52. Higgins J, Lee MK, Co C, Janusz MT (2014) Long-term outcomes after thoracic aortic surgery: A population-based study. J Thorac Cardiovasc Surg 148(1): 47-52.

53. Crawford ES, Crawford JL, Safi HJ, Coselli JS, Hess KR, et al. (1986) Thoracoabdominal aortic aneurysms: preoperative and intraoperative factors determining immediate and long-term results of operations in 605 patients. J Vasc Surg 3(3): 389-404.

54. Bischoff MS, Brenner RM, Scheumann J, Bodian CA, Griepp RB, et al. (2010) Long-term outcome after aortic arch replacement with a trifurcated graft. J Thorac Cardiovasc Surg 140(6 Suppl): S71-S76.

55. Estrera AL, Miller CC, Huynh TT, Porat EE, Safi HJ (2002) Replacement of the ascending and transverse aortic arch: determinants of long-term survival. Ann Thorac Surg 74(4): 1058-1064.

56. Kouchoukos NT, Kulik A, Castner CF (2013) Outcomes after thoracoabdominal aortic aneurysm repair using hypothermic circulatory arrest. J Thorac Cardiovasc Surg 145(3 Suppl): S139-S141.

57. Geisbuesch S, Schray D, Bischoff MS, Lin HM, Di Luozzo G, et al. (2012) Frequency of reoperations in patients with Marfan syndrome. Ann Thorac Surg 93(5): 1496-1501.

58. Lombardi JV, Carpenter JP, Pochettino A, Sonnad SS, Bavaria JE (2003) Thoracoabdominal aortic aneurysm repair after prior aortic surgery. J Vasc Surg 38(6): 1185-1190.

59. Olsson C, Thelin S, Ståhle E, Ekbom A, Granath F (2006) Thoracic aortic aneurysm and dissection: increasing prevalence and improved outcomes reported in a nationwide population-based study of more than 14,000 cases from 1987 to 2002 . Circulation 114(24): 2611-2618. 
This work is licensed under Creative Commons Attribution 4.0 License DOI: $10.19080 /$ JOCCT.2017.04.555629

\section{Your next submission with Juniper Publishers} will reach you the below assets

- Quality Editorial service

- Swift Peer Review

- Reprints availability

- E-prints Service

- Manuscript Podcast for convenient understanding

- Global attainment for your research

- Manuscript accessibility in different formats

( Pdf, E-pub, Full Text, Audio)

- Unceasing customer service

Track the below URL for one-step submission https://juniperpublishers.com/online-submission.php 